\title{
Ovarian Hemangioma: a rare entity
}

\section{Mona Dahal $^{1 *}$, Paricha Upadhyaya1 ${ }^{1}$, Purbesh Adhikari ${ }^{1}$, Diksha Karki ${ }^{1}$, Niraj Regmi ${ }^{2}$}

\author{
${ }^{1}$ Department of Pathology, ${ }^{2}$ Department of Radiodiagnosis and Imaging, B.P. Koirala Institute of Health Sciences, \\ Dharan, Nepal
}

Received: 22 April 2018

Accepted: 02 May 2018

\section{*Correspondence:}

Dr. Mona Dahal,

E-mail: monadahal@gmail.com

Copyright: (c) the author(s), publisher and licensee Medip Academy. This is an open-access article distributed under the terms of the Creative Commons Attribution Non-Commercial License, which permits unrestricted non-commercial use, distribution, and reproduction in any medium, provided the original work is properly cited.

\begin{abstract}
Ovarian hemangiomas are uncommon benign vascular tumors of ovary. Most of them are asymptomatic and detected incidentally during surgery. Authors report a case of 41 years female, parity 2; with complain of lower abdominal pain for 6 months. Ultrasonography showed a cystic lesion at right adnexa with a heterogeneously echogenic component within and devoid of internal vascularity. Laparoscopic right adnexal cystectomy was done, which on histopathological examination demonstrated features of cavernous hemangioma replacing the ovarian parenchyma. As surgical excision is treatment of choice, correct diagnosis is essential to avoid unnecessary radical surgery and treatment.
\end{abstract}

Keywords: Cavernous, Hemangioma, Ovary, Vascular

\section{INTRODUCTION}

Ovarian hemangiomas are uncommon benign vascular tumors of ovary, with approximately less than 60 cases reported in literature so far. Though, most of the ovarian hemangiomas are small in size and detected incidentally during surgery for other causes or autopsy, some patients can present with abdominal pain, abdominal swelling and mass or ascites. The cyclical changes in female genital organs during reproductive period and small size of these neoplasms have been attributed to the rarity of these lesions. Moreover, few cases of ovarian hemangiomas may not be identified or recorded. Histologically ovarian hemangiomas are either cavernous, capillary, or mixed type with most of them found to be of cavernous type. Microscopic examination reveals numerous thin walled dilated blood vessels lined by single layer of bland endothelial cells arranged haphazardly in the ovarian parenchyma or forming nodule.

There is presence of variable amount of connective tissue stroma showing inflammation, haemorrhage or hemosiderin deposits as well as calcification in occasional cases. Rarely ovarian hemangioma can coexist with hemangioma of female genital tract of other sites. The treatment of choice in ovarian hemangioma includes surgical excision of the tumor. ${ }^{1-4} \mathrm{We}$ report a case of ovarian hemangioma in a 41 years old female diagnosed in histopathological examination.

\section{CASE REPORT}

A 41 years old female (parity 2), presented in gynaecological outpatient clinic with complain of lower abdominal pain for 6 months. The pain was dull aching, non-radiating type and was more towards right side. Her menstrual history was normal and obstetric history was uneventful. She denied weight loss, fever, vomiting, vaginal discharge, male pattern hair growth and hair loss. The medical history was unremarkable except for history of cholecystectomy done for gall stone 8 years back. On bimanual pelvic examination, a right adnexal mass was palpated. Routine haematological and biochemical parameters as well urine analysis were within normal limits. Ultrasonography showed a cystic lesion of size 6.8 $\mathrm{x} 4.9 \mathrm{~cm}$ in right adnexa with a heterogeneously appearing isoechoic component in the nondependent wall of the cyst and devoid of internal vascularity on color 
Doppler study. (Figure1) Evidence of fluid collection was not seen.

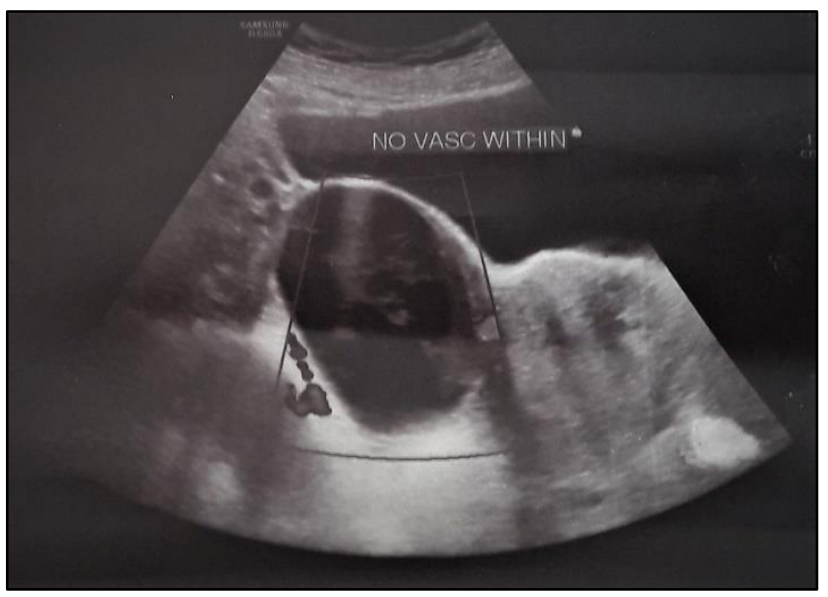

Figure 1: Ultrasound image showing a cystic lesion at right adnexa with a heterogeneously appearing isoechoic component in the nondependent wall of the cyst and devoid of internal vascularity on colour Doppler study.

The radiological differential diagnoses considered were Hemorrhagic Cyst and Dermoid Cyst. Laparoscopic right adnexal cystectomy was done.

Grossly multiple bits of greywhite to greybrown soft tissue measuring together $4 \times 3 \times 2 \mathrm{~cm}$ was submitted which on histological examination revealed a hemangioma of cavernous type exhibiting haphazardly arranged multiple thin walled dilated blood vessels within the ovarian parenchyma. (Figure 2) These vessels were lined by a single layer of flattened endothelial cells and were filled with red blood cells.

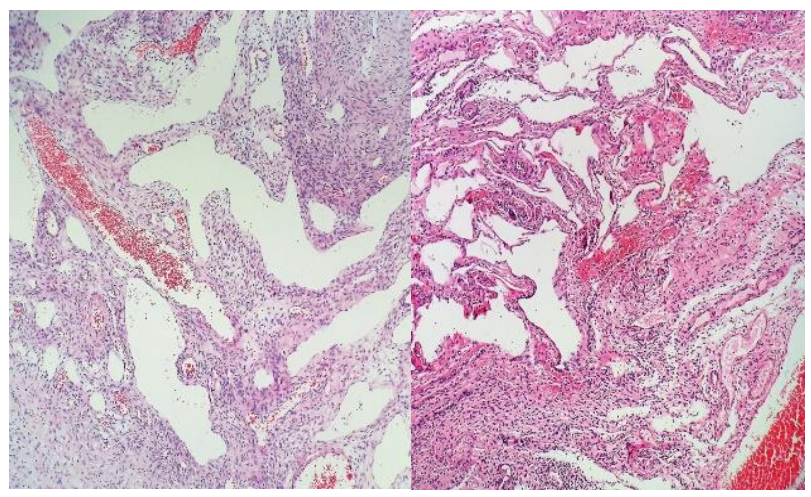

Figure 2: Multiple thin walled dilated vessels lined by single layer of bland endothelial cells within the ovarian parenchyma and filled with red blood cells (Hematoxylin and eosin stain, x200).

Nuclear atypia, necrosis and mitosis were not observed. Thrombi were noted within the lumen of few of the vessels. The ovary was entirely processed to exclude the possibility of teratoma with prominent vascular component.

\section{DISCUSSION}

Though ovary is highly vascularized organ, vascular tumors arising in ovary is extremely rare. Ovarian hemangioma was first described by Payne et al is 1869 in a 25-year-old female with bilateral ovarian hemangioma co-existing with abdominopelvic hemangiomatosis. ${ }^{5}$

These neoplasms can occur at any age and has been found in different ages ranging from 4 months to 81 years. Grossly the size of ovarian hemangioma has been found to be in the range of $0.3 \mathrm{~cm}$ to $24 \mathrm{~cm}$ and is usually unilateral with occasional bilateral cases. Most ovarian hemangiomas are asymptomatic and small. However, few larger tumors can present with abdominal distension due to mass or abdominal pain and vomiting due to torsion. Cases of ovarian hemangioma presenting with ascites and pleural effusion (pseudo-Meigs' Syndrome), thrombocytopenia (Kasabach Merritt syndrome) and elevated CA 125 mimicking ovarian surface epithelial tumors have also been reported., ${ }^{3,5,6}$ Thus ovarian hemangioma can present with signs and symptoms similar to epithelial malignancies and misdiagnosis can lead to unnecessary radical surgery and treatment.

Ovarian hemangioma may synchronously occur in patients with ovarian neoplasm such as Mature Cystic Teratoma of contralateral ovary, papillary serous carcinoma and mucinous cystadenoma as well as nonovarian neoplasms such as hyperplasia, polyp or carcinoma of endometrium, cervical carcinoma, tubal carcinoma or rectosigmoid carcinoma. Association of ovarian hemangioma with tamoxifen therapy for breast ductal carcinoma has also been noted..$^{5,8,9}$

The etiology and pathogenesis of ovarian hemangioma is unknown and different theories have been proposed to explain its etiopathogenesis. A controversy exists to consider ovarian hemangioma as hamartoma, true neoplasm or congenital malformation. However hormonal factors, pregnancy and infection have been implicated for the growth of these tumors. As estrogen has a growth stimulatory effect on vasculature, hyperestrogenism due to pre-existing stromal luteinisation has been implicated for pathogenesis of ovarian hemangioma by some authors. Miliars et al have found endothelial cells to be immunopositive for Estrogen Receptor (ER) and Progesterone Receptor (PR) in their case. ${ }^{1,5}$

Coexistence of stromal luteinisation with ovarian hemangioma due to the pressure effect induced by the proliferating hemangioma has also been proposed in the literature, as evident by presence of luteinized stromal cells within the stroma of the lesion or ovarian parenchyma surrounding the lesion. The neoplastic endothelial cells can also secrete stroma stimulating 
substance leading to stromal luteinisation. The luteinized stromal cells produce androgen and subsequently estrogen in adipose tissue leading to virilisation, male pattern hair loss, and endometrial hyperplasia in few reported cases. However, stromal luteinisation and features of hyperandrogenism and hyperestrogenism was not seen in our case. ${ }^{1,5,10}$

The preoperative differential diagnoses of these tumors include twisted ovarian cyst and chocolate cyst. Few nonspecific radiological features of ovarian hemangioma have been proposed like complex mass with solid and cystic component on Computed Tomography (CT) scan and marked enhancement pattern with contrast enhanced T1 weighted images on Magnetic Resonance Imaging (MRI) scan. However, Kim et al have reported heavily calcified ovarian cavernous hemangioma, which did not show such enhancement pattern in CT scan or MRI. The differential diagnoses in such cases include degenerated uterine or intraligamentous myoma, or an ovarian tumor like fibrothecoma, Brenner tumor and mature or immature teratoma. ${ }^{2,3,11}$

The main pathological differential diagnoses of ovarian hemangioma are closely packed ovarian medullary blood vessels in postmenopausal women and proliferating hilar blood vessels. However, such vascular proliferations do not form distinct mass and are admixed with nerve fibres and lymphatic vessels. Other differential diagnoses are lymphangioma, angiosarcoma and teratoma with hemangiomatous component.

The absence of pale eosinophilic secretion within the vascular channel excluded lymphangioma in our case. Features of angiosarcoma like increased mitosis, cytological atypia and necrosis was not seen. The ovary was entirely processed to exclude the presence of other teratomatous component. ${ }^{3,5}$

\section{CONCLUSION}

In summary ovarian hemangioma are rare benign vascular tumors with a wide age range and should be considered in the differential diagnosis of hemorrhagic ovarian lesion. A correct preoperative and postoperative diagnosis is necessary to avoid unnecessary radical surgery and radiotherapy and chemotherapy. The patients of ovarian hemangioma should be thoroughly evaluated to exclude other ovarian and non-ovarian neoplasms as well.

Funding: No funding sources

Conflict of interest: None declared

\section{Ethical approval: Not required}

\section{REFERENCES}

1. Huang RSP, Covinsky M, Zhang S. Bilateral ovarian capillary hemangioma with stromal luteinization and hyperandrogenism. Ann Clin Lab Sci. 2013;43:4579.

2. Mitra B, Sengupta S, Rai A, Mehta J, Quader AR, Roy S, et al. Ovarian haemangioma: A rare case report. Int J Surg Case Rep. 2013;4:981-4.

3. Kim SS, Han SE, Lee NK, Choi KU, Joo JK, Suh DS, et al. Ovarian cavernous hemangioma presenting as a large growing mass in a postmenopausal woman: a case report and review of the literature. J Menopausal Med. 2015; 21:155.

4. Bolat F, Erkanli S, Kocer NE. Ovarian hemangioma: report of two cases and review of the literature. Turkish J Pathol. 2010; 26:264.

5. Hasan Al-Shaikh SAA. Ovarian hemangioma presenting with ascites and elevated CA125. J Cytol Histol. 2016;7:409

6. Gehrig PA, Fowler WC, Lininger RA. Ovarian capillary hemangioma presenting as an adnexal mass with massive ascites and elevated CA-125. Gynecol Oncol. 2000;76(1):130-2.

7. Bayramoğlu $H$, Güngör $T$, Öz $M$, Doğan NU, Reyhan H, Beşli M. Primary ovarian hemangioma: case report and review of literature. Med J Islam World Acad Sci. 2012;20:106-10.

8. Comunoglu C, Atasoy L, Baykal C. Ovarian hemangioma occurring synchronously with contralateral mature cystic teratoma in an 81-yearold patient. Ups J Med Sci. 2010;115(4):297-9.

9. Lanzafame S, Caltabiano R, Nicolosi AG, Palmeri S. Ovarian hemangioma associated with tamoxifen therapy: a case report. Gynecol Surg. 2008; 5:65-8.

10. Anbardar M, Azarpira N, Robati M, Shirazi B. An incidental ovarian mass: A case of ovarian hemangioma with prominent stromal luteinization. Med J Dr DY Patil Univ. 2015;8:227.

11. Kim MY, Rha SE, Oh SN, Lee YJ, Jung ES, Byun JY. Ovarian cavernous haemangioma presenting as a heavily calcified adnexal mass. Br J Radiol. 2008; 81:e269-71.

Cite this article as: Dahal $\mathrm{M}$, Upadhyaya $\mathrm{P}$, Adhikari P, Karki D, Regmi N. Ovarian Hemangioma: A rare entity. Int J Reprod Contracept Obstet Gynecol 2018;7:2490-2. 